\title{
Preconcentration and Determination of Tin in Water Samples by Using Cloud Point Extraction and Graphite Furnace Atomic Absorption Spectrometry
}

\author{
Chun-Gang Yuan, Gui-Bin Jiang*, Bin He, and Jing-fu Liu \\ State Key Laboratory of Environmental Chemistry and Ecotoxicology, Research Center for Eco-Environmental Sciences, \\ Chinese Academy of Sciences, P.O. Box 2871, 100085 Beijing, China
}

Received May 17, 2004; accepted April 5, 2005; published online June 9, 2005

(C) Springer-Verlag 2005

\begin{abstract}
A method based on cloud point extraction and graphite furnace atomic absorption spectrometry (GFAAS) was developed for the analysis of trace tin in water samples. After cloud point extraction, the tin in the water samples was preconcentrated and successfully separated from most interferents. During the procedure, 8-hydroxyquinoline (8-HQ) was used as chelating reagent, and Triton $\mathrm{X}-114$ was added as surfactant. The parameters affecting the sensitivity and the extraction efficiency, such as solution $\mathrm{pH}$, concentration of 8-HQ and Triton X-114, equilibration temperature and centrifuge time, were evaluated and optimized. Under the optimum conditions, a preconcentration factor of 96.2 was obtained for a $20 \mathrm{~mL}$ water sample. The detection limit (LOD) was as low as $0.012 \mathrm{ng} \mathrm{mL}^{-1}$, and the analytical curve was linear in the range of $0.05-$ $2.0 \mathrm{ng} \mathrm{mL}^{-1}$ with satisfactory precision $(\mathrm{RSD}<4.1 \%$ ). The proposed method was successfully applied to the determination of trace tin in water samples with recoveries in the range of $85.0-112.0 \%$.
\end{abstract}

Key words: Cloud point extraction; graphite furnace atomic absorption spectrometry; tin determination; water.

The determination of tin in the environment has become an important task because of the wide industrial

\footnotetext{
* Author for correspondence. Email: gbjiang@mail.rcees.ac.cn
}

use of tin compounds in the past decades and their diverse effects on human health. A reliable instrument for routine determination of tin is graphite furnace atomic absorption spectrometry (GFAAS). However, the tendency of tin to form volatile compounds which are easily lost during the drying and ashing steps, and the interaction of tin with the furnace wall [1] are two major problems of tin determination by GFAAS. Previous studies have tried to overcome these problems, e.g. by coating graphite tubes with certain elements (W, Ta, Zr, Mo and La) [2-7] and using matrix modifiers [8-12]. However, interferences in real samples cannot be avoided completely, so separation of the analytes from the complex matrix is always necessary [2]. In water samples there are many interferents, especially chloride and sulfide salts, which constitute the most frequent interferences in graphite furnace atomic absorption spectrometry (GFAAS) [13]. In addition, the concentrations of tin in water samples are generally very low and it is not possible to determine such an analyte in a complex sample when its concentration is below the quantification limit of the instrument used. Therefore the separation and preconcentration techniques play important roles. To preconcentrate and decrease the loss of tin during the determination procedure by ETAAS, Borba da Silva [14] applied anodic electro-dissolution in a flow 
injection system. After the electrolyzed material was collected in the autosampler cup, determination was carried out using electrothermal atomic absorption spectrometry (ETAAS). To do so, hydride generation techniques are also used sometimes [2, 15, 16]. These techniques are effective and useful for analysis of trace tin. However, they all require special instruments, which not only make the method complex and time-consuming but also unavailable to many laboratories. In recent years, solid phase extraction (SPE) techniques with high preconcentration factors have become popular, and these methods have also been used for the preconcentration of tin and tin compounds in water samples [17, 18]. However, a relatively larger volume of water sample is always needed when applying this technique. Unfortunately, the water sample volumes are usually limited for some reasons. Compared with the methods described above, solvent extraction is the most widely used and traditional technique for the pre-concentration of tin from various complex samples $[19,20]$. This technique is readily available and practical for most laboratories. However, it always involves large amounts of organic solvents, which not only make the method costly but also hazardous.

Compared with traditional liquid-liquid extraction, cloud point extraction is advantageous due to the fact that it uses a very small amount of relatively nonflammable and nonvolatile surfactants during the extraction procedure. As a new and environmentally friendly liquid-liquid extraction method, cloud point extraction (CPE) has been employed in analytical chemistry to separate and preconcentrate both organic compounds [21-23] and metal ions [24-30] in recent years. Compared with other methods reported for the preconcentration of tin, especially the traditional liquid-liquid extraction method, CPE can yield high enrichment factors with relatively small volumes of samples, it is simple and safe and requires no additional special instruments or dangerous solvents. Stalikas reviewed the development of CPE as a reliable tool of separation and preconcentration in metal analysis [31].

The aim of this paper is to develop a simple, sensitive and available method for the preconcentration and determination of trace tin in water by using graphite furnace atomic absorption spectrometry with CPE. After cloud point extraction, tin in samples was separated from the matrix and preconcentrated with a high enrichment factor (96.2). Using the matrix modifier (palladium-magnesium nitrate) and zirconium-coated graphite tube, this method was applied to the determination of trace tin in water samples with satisfactory recoveries.

\section{Experimental}

\section{Apparatus}

A Hitachi Z-5700 graphite furnace atomic absorption spectrometer (Hitachi High-Technologies Corporation, Japan) equipped with Zeeman background correction was used. A tin hollowcathode lamp was used as radiation source at $224.6 \mathrm{~nm}$. The optimum operating parameters for the spectrometer are shown in Table 1. A $20 \mu \mathrm{L}$ aliquot of sample was manually injected into the furnace, and absorbance signals in the form of peak height were measured. A thermostated bath (TB-85 Therma Bath, Shimadu, Japan) maintained at the desired temperature was applied to obtain cloud point preconcentration. A centrifuge and calibrated centrifuge tubes (Beijing Medicinal Instrument Company, China) were used to accelerate the phase separation process.

\section{Reagents}

All reagents were of analytical grade, and deionized water $(18 \mathrm{M} \Omega)$ obtained from Easypure System (Model D7382-33, Barnstead Thermolyne Corporation, U.S.A.) was used throughout. The stock

Table 1. Instrumental operating conditions

\begin{tabular}{|c|c|c|c|c|}
\hline $\begin{array}{l}\text { Lamp current } / \mathrm{mA} \\
\text { Wavelength/nm } \\
\text { Slit/nm }\end{array}$ & $\begin{array}{r}14 \\
224.6 \\
1.3\end{array}$ & & $\begin{array}{l}\text { Cuvette } \\
\text { Gas flow } / \mathrm{mL} \mathrm{min}^{-1} \\
\text { Sample volume } / \mu \mathrm{L}\end{array}$ & $\begin{array}{l}\text { Zr-coated tube } \\
30 \\
20\end{array}$ \\
\hline \multicolumn{5}{|l|}{ Temperature program } \\
\hline \multirow[t]{2}{*}{ Stage } & \multicolumn{2}{|c|}{ Temperature $/{ }^{\circ} \mathrm{C}$} & \multirow[t]{2}{*}{ Ramp time/s } & \multirow[t]{2}{*}{ Hold time/s } \\
\hline & Start & End & & \\
\hline Drying & 80 & 140 & 40 & \\
\hline Ashing & 700 & 700 & 20 & \\
\hline Atomizing & 2600 & 2600 & & 5 \\
\hline Cleaning & 2800 & 2800 & & 4 \\
\hline
\end{tabular}


standard solution of Sn (IV) $\left(1000 \mu \mathrm{g} \mathrm{mL}^{-1}\right)$ was obtained by dissolving $1.0000 \mathrm{~g}$ of tin metal in $100 \mathrm{~mL}$ concentrated hydrochloric acid and $5 \mathrm{~mL}$ concentrated nitric acid, and diluting to $1000 \mathrm{~mL}$ with deionized water. Working standard solutions were obtained by appropriate dilution of the stock standard solution with $2 \%$ hydrochloric acid $(\mathrm{V} / \mathrm{V})$. The non-ionic surfactant Triton X-114 (Acros Organics, U.S.A.) was used without further purification. 8-HQ aqueous solution was prepared by dissolving appropriate amounts of 8-HQ (Beijing Chemical Factory, China) in methanol and then diluting with deionized water.

The materials and vessels used for trace analysis were kept in $10 \%$ nitric acid for at least $48 \mathrm{~h}$ and subsequently washed four times with deionized water before use.

\section{Cloud Point Extraction Procedure}

For the preconcentration of Sn (IV), aliquots of $20.0 \mathrm{~mL}$ of the cold solution containing the analyte with the final concentration of Triton X-114 2.0 $\mathrm{g} \mathrm{L}^{-1}$ and 8-HQ $1 \times 10^{-5} \mathrm{~g} \mathrm{~mL}^{-1}$, buffered at $\mathrm{pH} 3.0$, were mixed and left in the thermostatic bath $\left(40^{\circ} \mathrm{C}\right)$ for $20 \mathrm{~min}$. Then the phase separation was accelerated by centrifugation for $6 \mathrm{~min}$ at $3000 \mathrm{rpm}$. On cooling in an ice-bath, the surfactant-rich phase was separated with the aid of a syringe. After removing the bulk aqueous phase, the remaining micellar phase (about $100 \mu \mathrm{L}$ ) was treated with $100 \mu \mathrm{L}$ of the methanolic solution containing $1 \%(\mathrm{v} / \mathrm{v})$ nitric acid to reduce its viscosity. $20 \mu \mathrm{L}$ samples were introduced into the GFAAS by manual injection. During the experiment, $20 \mu \mathrm{L} 200 \mathrm{mg} \mathrm{L}^{-1} \mathrm{Pd}-\mathrm{Mg}\left(\mathrm{NO}_{3}\right)_{2}$ as chemical modifier was applied throughout before each injection.

\section{Extraction of Tin in Real Samples}

The water samples were filtered through a $0.45 \mu \mathrm{m}$ pore size membrane filter to remove suspended particulate matter. $10 \mathrm{~mL}$ concentrated nitric acid and $10 \mathrm{~mL} \mathrm{H}_{2} \mathrm{O}_{2}$ was added to a $100 \mathrm{~mL}$ water sample and heated at $60^{\circ} \mathrm{C}$ for $12 \mathrm{~h}$ to decompose the organic tin compounds. After that the water samples were adjusted to $\mathrm{pH} 3.0$ by adding ammonia, and the volume was made up to $100 \mathrm{~mL}$. Finally, a $20 \mathrm{~mL}$ water sample was submitted to the cloud point extraction procedure.

\section{Results and Discussion}

\section{Effect of $p H$}

The separation of metal ions by cloud point extraction involves prior formation of a complex with sufficient hydrophobicity which can be extracted into the small volume of surfactant-rich phase, thus yielding the desired preconcentration. To investigate the effect of $\mathrm{pH}$ on the extraction efficiency, cloud point extraction of tin was performed at different $\mathrm{pH}$ values. The results are shown in Fig. 1. It was found that atomic absorbance reached a maximum at $\mathrm{pH}$ 3.0, indicating that maximum extraction efficiency was obtained. During the experiment, $\mathrm{pH} 3.0$ was selected as the working acidity.

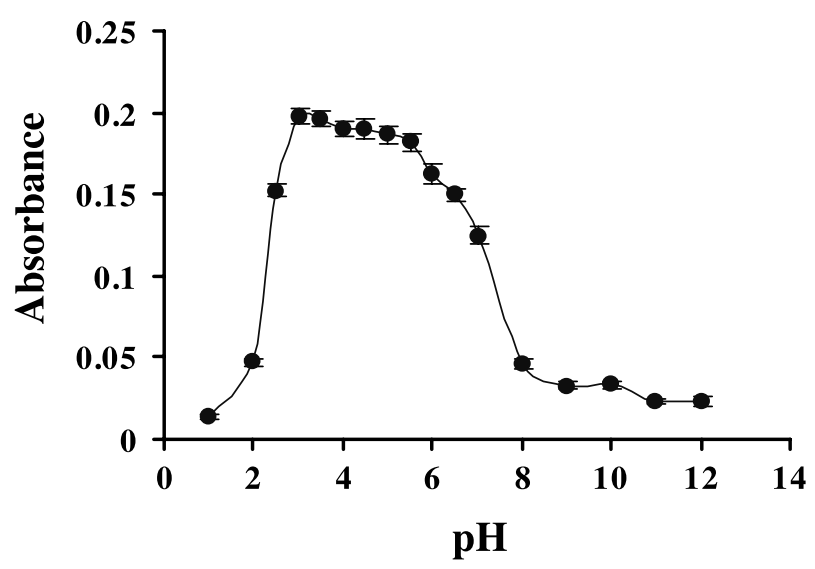

Fig. 1. Effect of $\mathrm{pH}$ on preconcentration of $\mathrm{Sn}$ (IV). Conditions: $1.0 \mathrm{ng} \mathrm{mL}^{-1} \mathrm{Sn}$ (IV) $20 \mathrm{~mL}, 1 \times 10^{-5} \mathrm{~g} \mathrm{~mL}^{-1} 8-\mathrm{HQ}, 2.0 \mathrm{~g} \mathrm{~L}^{-1}$ Triton X-114 at $40^{\circ} \mathrm{C}$. Other experimental conditions described in the Cloud point extraction procedure section

\section{Effect of 8-HQ Concentration}

In general, the concentration of the chelating reagent has a remarkable influence on the extraction efficiency. In order to select the optimal concentration of 8-HQ, with the other experimental parameters remaining constant, the effect of the chelating reagent's concentration on the extraction efficiency was examined. The results are presented in Fig. 2. They indicate that the maximum signal was obtained at $1 \times 10^{-5} \mathrm{~g} \mathrm{~mL}^{-1} \quad 8$-HQ $\left(-\log \mathrm{C}_{8-\mathrm{HQ}}=5\right)$. Therefore, $1 \times 10^{-5} \mathrm{~g} \mathrm{~mL}^{-1} 8$-HQ was chosen as the optimum concentration of the chelating reagent.

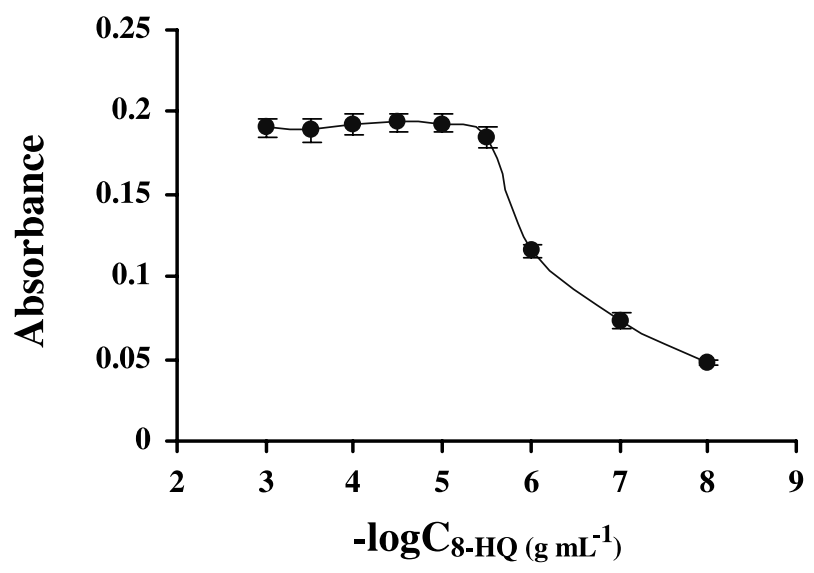

Fig. 2. Influence of 8 -HQ concentration on the absorbance signal of Sn (IV). Conditions: $1.0 \mathrm{ng} \mathrm{mL}^{-1} \mathrm{Sn}$ (IV) $20 \mathrm{~mL}$, pH $3.0,2.0 \mathrm{~g} \mathrm{~L}^{-1}$ Triton $\mathrm{X}-114$ at $40^{\circ} \mathrm{C}$. Other experimental conditions described in the Cloud point extraction procedure section 


\section{Effect of Triton X-114 Concentration}

For a successful cloud point extraction procedure, Triton X-114 was chosen for the formation of the surfactant-rich phase due to its low cloud point temperature $\left(23-25^{\circ} \mathrm{C}\right)$ and high density of the surfactant-rich phase [32]. The properties of Triton $\mathrm{X}-114$ facilitate the extraction procedure and phase separation by centrifugation. In this experiment, the extraction efficiency was investigated upon varying surfactant concentration in the range of $0.1-6.0 \mathrm{~g} \mathrm{~L}^{-1}$, the results of which are shown in Fig. 3. The atomic absorption reached its maximum at $2.0 \mathrm{~g} \mathrm{~L}^{-1}$ of Triton $\mathrm{X}-114$, indicating that quantitative extraction by cloud point method was obtained. With the Triton X-114 concentration increasing above $2.5 \mathrm{~g} \mathrm{~L}^{-1}$, the signal decreased because of the increment of the volume and the viscosity of the surfactant phase. Based on the experimental results, $2.0 \mathrm{~g} \mathrm{~L}^{-1}$ Triton X-114 was adopted as optimal for the largest analytical signal and the highest extraction efficiency.

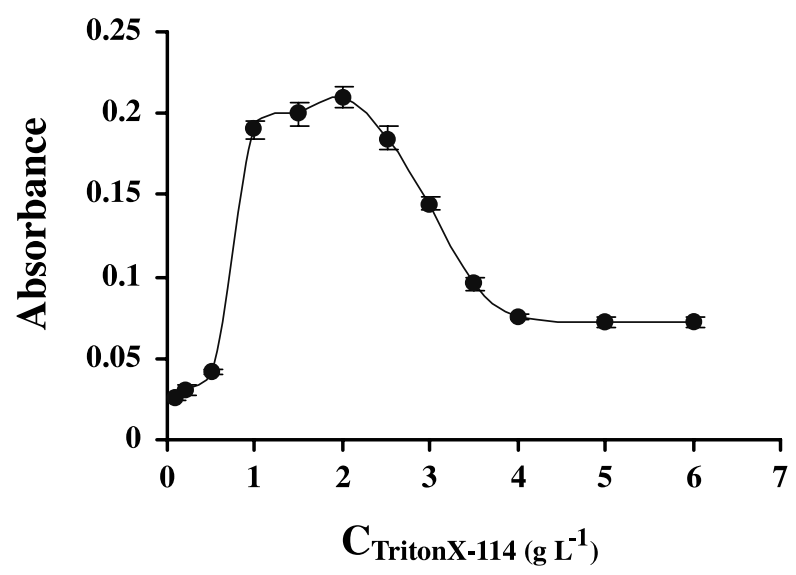

Fig. 3. Variation of the analytical signal of Sn (IV) with Triton $\mathrm{X}-114$ concentrations. Conditions: $1.0 \mathrm{ng} \mathrm{mL}^{-1} \mathrm{Sn}$ (IV) $20 \mathrm{~mL}$, $\mathrm{pH} 3.0,1 \times 10^{-5} \mathrm{~g} \mathrm{~mL}^{-1} 8$-HQ at $40^{\circ} \mathrm{C}$. Other experimental conditions described in the Cloud point extraction procedure section

\section{Effect of Equilibration Temperature and Centrifuge Time}

The greatest analyte preconcentration factor was achieved when the cloud point extraction procedure was performed at equilibration temperatures that were well above the cloud point temperature of the surfactant [33]. So it is necessary to examine the effect of temperature on cloud point extraction. In order to achieve the shortest incubation time and the lowest possible equilibration temperature, and to ensure the reaction is complete and the separation of phases is efficient, the effect of equilibration temperature and time were examined. Maximum signals were obtained at temperatures between 35 and $70^{\circ} \mathrm{C}$. At $20^{\circ} \mathrm{C}$, which was below the cloud point temperature of Triton X-114, the two phases cannot be formed and the metal complex cannot be extracted. When the temperature is above $70^{\circ} \mathrm{C}$, the signal decreases due to the decomposition of the complex. Therefore, $40^{\circ} \mathrm{C}$ was selected as the working equilibration temperature. The equilibration time was also selected for the best signal and efficient extraction in the time span of 5-60 min. It was found that an incubation time of $15 \mathrm{~min}$ was sufficient for quantitative extraction. $15 \mathrm{~min}$ was chosen as the equilibration time in this experiment.

The effect of centrifuge time on the extraction efficiency was studied in the time range of $1-30 \mathrm{~min}$ at $3000 \mathrm{rpm}$. The results showed that there are no appreciable improvements for a time longer than $5 \mathrm{~min}$ when complete separation occurs. A centrifuge time of 6 min was selected as optimum.

\section{Figures of Merit}

Calibration graphs were obtained by preconcentrating $20 \mathrm{~mL}$ of standard $\mathrm{Sn}$ (IV) solution with $2.0 \mathrm{~g} \mathrm{~L}^{-1}$ Triton X-114, under the experimental conditions specified in the procedure. The surfactant-rich phase was

Table 2. Analytical characteristics of the method

\begin{tabular}{|c|c|c|c|c|c|}
\hline Element conditions & $\begin{array}{l}\text { Concentration } \\
\text { range }\left(\mathrm{ng} \mathrm{mL}^{-1}\right)\end{array}$ & Regression equation & $\mathrm{R}^{2}$ & $\begin{array}{l}\text { D.L. } \\
\left(\text { ng } \mathrm{mL}^{-1}\right)^{\mathrm{b}}\end{array}$ & $\begin{array}{l}\text { R.S.D. }(\%) \\
(\mathrm{n}=5)\end{array}$ \\
\hline Sn without preconcentration & $10-200$ & $\mathrm{~A}=0.0022 \mathrm{C}-0.0027$ & 0.9995 & 1.5 & $2.7(60)^{\mathrm{c}}$ \\
\hline $\begin{array}{l}\text { Sn with preconcentration } \\
\text { by Triton } \mathrm{X}-114^{\mathrm{a}}\end{array}$ & $0.05-2.0$ & $\mathrm{~A}=0.2116 \mathrm{C}+0.0016$ & 0.9916 & 0.012 & $4.1(1.0)^{\mathrm{c}}$ \\
\hline
\end{tabular}


diluted with $100 \mu \mathrm{L}$ of a solution of methanol containing $1 \%(\mathrm{~V} / \mathrm{V})$ nitric acid to reduce its viscosity. $20 \mu \mathrm{L}$ of diluted solution was introduced into GFAAS by manual injection. Table 2 gives the parameters of the calibration graphs and also shows the calibration parameters obtained with standard solutions of Sn (IV) not subjected to the proposed preconcentration method. The calibration curve for Sn (IV) was rectilinear from 0.05 to $2.0 \mathrm{ng} \mathrm{mL}^{-1}$ with a satisfactory relative standard deviation $(4.1 \%$ at $1.0 \mathrm{ng} \mathrm{mL}^{-1}$ ) and detection limit $(3 \sigma)$ (reagent blank, $\mathrm{n}=7$ ) as low as $0.012 \mathrm{ng} \mathrm{mL}^{-1}$. The enrichment factor of 96.2 was obtained by preconcentrating $20 \mathrm{~mL}$ solution.

Table 3. Influence of foreign ions on the preconcentration and determination of $\operatorname{tin}^{\mathrm{a}}$

\begin{tabular}{llr}
\hline Foreign ion & $\begin{array}{l}\text { Foreign ion } \\
\text { to analyte ratio }\end{array}$ & Recovery $(\%)^{\mathbf{b}}$ \\
\hline $\mathrm{Cl}^{-}$ & $1 \times 10^{6}$ & \\
$\mathrm{SO}_{4}{ }^{2-}$ & $1 \times 10^{6}$ & $92.3 \pm 1.9$ \\
$\mathrm{HCO}_{3}{ }^{-}$ & $1 \times 10^{4}$ & $95.6 \pm 2.3$ \\
$\mathrm{CO}_{3}{ }^{2-}$ & $1 \times 10^{4}$ & $98.4 \pm 3.9$ \\
$\mathrm{NO}_{3}{ }^{-}$ & $1 \times 10^{4}$ & $102.3 \pm 3.2$ \\
$\mathrm{~F}^{-}$ & $1 \times 10^{4}$ & $96.8 \pm 1.7$ \\
$\mathrm{Fe}^{3+}$ & 2000 & $93.2 \pm 1.1$ \\
$\mathrm{Fe}^{2+}$ & 2000 & $94.5 \pm 3.4$ \\
$\mathrm{Mg}^{2+}$ & 2000 & $90.8 \pm 2.7$ \\
$\mathrm{Al}^{3+}$ & 1000 & $106.8 \pm 1.5$ \\
$\mathrm{Cu}^{2+}$ & 1000 & $82.3 \pm 2.0$ \\
$\mathrm{Zn}^{2+}$ & 500 & $91.8 \pm 3.7$ \\
$\mathrm{Cr}^{3+}$ & 500 & $92.3 \pm 3.1$ \\
$\mathrm{Mn}^{2+}$ & 500 & $104.1 \pm 2.1$ \\
$\mathrm{Co}^{2+}$ & 500 & $81.8 \pm 4.0$ \\
$\mathrm{Ni}^{2+}$ & 500 & $91.3 \pm 1.9$ \\
$\mathrm{~Pb}^{2+}$ & 500 & $102.9 \pm 3.6$ \\
$\mathrm{Hg}^{2+}$ & 100 & $90.6 \pm 2.8$ \\
\hline
\end{tabular}

a Preconcentration step: $1.0 \mathrm{ng} \mathrm{mL}^{-1} \mathrm{Sn}$ (IV) $20 \mathrm{~mL}$, pH 3.0 , $1 \times 10^{-5} \mathrm{~g} \mathrm{~mL}^{-1} 8$-HQ, $2.0 \mathrm{~g} \mathrm{~L}^{-1}$ Triton X-114 at $40^{\circ} \mathrm{C}$.

${ }^{\mathrm{b}}$ Mean \pm standard deviation $(95 \%$ confidence interval, $\mathrm{n}=5)$.

\section{Interferences}

Cations that may react with 8-HQ and anions that may form complexes with tin were the two main types of interference affecting the preconcentration process. The effects of representative potential interfering species were tested, and the results are listed in Table 3. They show that the recoveries are quantitative and satisfactory in the presence of most foreign cations.

\section{Real Sample Analysis}

The method was applied to determine the concentrations of tin in water samples. Seawater was collected from the East China Sea, and river water was collected from Haihe River, Tianjin, China. Tap water was collected directly at the laboratory. $20 \mathrm{~mL}$ of each water sample was preconcentrated by the proposed method. Recovery tests were carried out with standard tin spiked in the real water samples. The results are shown in Table 4. They indicate that the method can be applied to real water samples with satisfactory recoveries.

Compared with other extraction methods such as conventional liquid-liquid extraction, cloud point extraction (CPE) exhibits much more environmentally friendly properties, and it is safer because small volumes of innoxious surfactants are used instead of toxic organic solvents. The surfactant is easily introduced into GFAAS by manual injection after diluting it with methanolic solution containing nitric acid. Interferences from anions such as chlorine and humic acid can be avoided since metal complexes are separated from them. Under the optimum conditions, a preconcentration factor of 96.2 was obtained for $20 \mathrm{~mL}$ water sample. The detection limit (LOD) was as low as $0.012 \mathrm{ng} \mathrm{mL}^{-1}$ and the analytical curve was

Table 4. Determination of tin in real and spiked samples

\begin{tabular}{lllrr}
\hline Sample & Measured $\left(\mathrm{ng} \mathrm{mL}^{-1}\right)^{\mathrm{a}}$ & Spiked $\left(\mathrm{ng} \mathrm{mL}^{-1}\right)$ & Found $\left(\mathrm{ng} \mathrm{mL}^{-1}\right)^{\mathrm{a}}$ & Recovery $^{\mathrm{b}}(\%)$ \\
\hline Sea water & $0.36 \pm 0.015$ & 0.20 & $0.54 \pm 0.011$ & 90.0 \\
& & 0.40 & $0.73 \pm 0.018$ & 92.5 \\
River water & \multirow{2}{*}{$0.12 \pm 0.008$} & 0.80 & $1.12 \pm 0.021$ & 95.0 \\
& & 0.10 & $0.21 \pm 0.016$ & 90.0 \\
Tap water & ND & 0.20 & $0.29 \pm 0.020$ & 85.0 \\
& & 0.50 & $0.68 \pm 0.031$ & 112.0 \\
& & 0.10 & $0.092 \pm 0.004$ & 92.0 \\
\end{tabular}

\footnotetext{
${ }^{\mathrm{a}}$ Mean \pm standard deviation $(95 \%$ confidence interval, $\mathrm{n}=5$ ).

b $100 \times[$ (found-base $) /$ spiked].
} 
linear in the range of $0.05-2.0 \mathrm{ng} \mathrm{mL}^{-1}$ with satisfactory precision. This experiment proved that the proposed method is convenient, safe, simple, rapid and inexpensive for the determination of tin in water samples.

Acknowledgments. This study was jointly supported by the National Basic Research Program of China (2003CB415001) and the National Natural Science Foundation of China (20205008).

\section{References}

[1] Lündberg E, Bergmark B, Frech W (1982) Anal Chim Acta 142: 129

[2] Zhe-ming N, Heng-bin H, Ang L, Bin H, Fu-zheng X (1991) J Anal At Spectrom 6: 385

[3] Vickrey T M, Harrison G V, Ramelow G J (1981) Anal Chem 53: 1573

[4] Zhou L, Chao T T, Meier A L (1984) Talanta 31: 73

[5] Zolka V J (1978) Anal Chem 50: 538

[6] Fritzsche H, Wegscheider W, Knapp G, Ortner G (1979) Talanta 26: 219

[7] Iwamoto E, Shimazu H, Yokota K, Kumamaru T (1992) J Anal At Spectrom 7: 421

[8] Pinel R, Benabdallad M Z, Astruc A, Astruc M (1986) Anal Chim Acta 181: 187

[9] Ferri T, Cardarelli E, Petronio B M (1989) Talanta 36: 513

[10] Mickie J C (1987) Anal Chim Acta 197: 303

[11] Schlemmer G, Welz B (1986) Spectrochim Acta Part B 41: 1157

[12] Bermejo-Barrera P, Soto-Ferreiro R M (1993) Fresenius' J Anal Chem 345: 60

[13] Özcan M, Akman S (2000) Spectrochim Acta Part B 55: 509

[14] Borba da Silva J B, Giacomelli M B O, Goncalves de Souza I, Curtius A J (1998) Talanta 47: 1191
[15] Moreda-Piñeiro J, López-Mah'ýa P, Muniategui-Lorenzo S, Fernández-Fernández E, Prada-Rodr'ýguez D (2002) Anal Chim Acta 461: 261

[16] Burguera M, Burguera J L, Rivas C, Carrero P, Brunetto R, Gallignani M (1995) Anal Chim Acta 308: 339

[17] Puri B K, Muñoz-Olivas R, Cámara C (2004) Spectrochim Acta Part B 59: 209

[18] Bermejo-Barrera P, Gonzalez-Campos G, Ferron-Novais M (1998) Talanta 46: 1479

[19] Venkaji K, Naidu P P, Rao T J P (1994) Talanta 41: 1281

[20] Dadfarnia S, Thompson K C, Hoult G (1994) J Anal At Spectrom 9: 7

[21] Bai D S, Li J L, Chen S B, Chen B H (2001) Environ Sci Technol 35: 3936

[22] Casero I, Sicilia D, Rubio S, Pérez-Bendito D (1999) Anal Chem 71: 4519

[23] Carabias-Martínez R, Rodríguez-Gonzalo E, DomínguezAlvarez J, Hernández-Méndez J (1999) Anal Chem 71: 2468

[24] Bezerra M A, Onceição A L B, Ferreira S L C (2004) Anal Bioanal Chem 378: 798

[25] Shemirani F, Abkenar S D, Mirroshandel A A, Niasari M S, Kozania R R (2003) Anal Sci 19: 1453

[26] Lazaro Gallindo Borges D, Mesquita Silva Da Veiga M A, Azzolin Frescura V L, Welz B, Curtius A J (2003) J Anal At Spectrom 18: 501

[27] Manzoori J L, Karim-Nezhad G (2003) Anal Chim Acta 484: 155

[28] Paleologos E K, Giokas D L, Tzouwara-Karayanni S M, Karayannis M I (2002) Anal Chim Acta 458: 241

[29] Wuilloud G M, Wuilloud J C A, Wuilloud R G, Silva M F, Olsina R A, Martinez L D (2002) Talanta 58: 619

[30] Wuilloud J C A, Wuilloud R G, Silva M F, Olsina R A, Martinez L D (2002) Spectrochim Acta Part B 57: 365

[31] Stalikas C D (2002) Trends Anal Chem 21: 343

[32] Hinze W L, Pramauro E (1993) Crit Rev Anal Chem 24: 133

[33] Frankewich P, Hinze W L (1994) Anal Chem 66: 944 